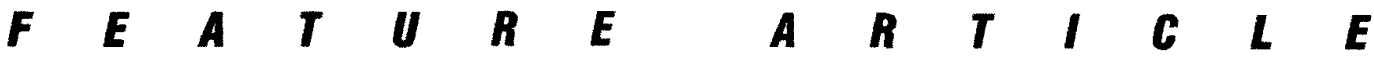

\section{Experiences with Digital Analysis of Discharges in High Voltage Components}

Key Words: Partial discharge, measurements, diagnostics, pattern recognition, high voltage equipment, insulation condition

$\mathrm{T}$ he main goal of PD diagnosis is to recognize high voltage insulation problems and to identify the insulation defect causing the discharge: e.g., internal or surface discharges, corona, treeing, etc. This information is vital for estimating the harmfulness of the discharge.

Manufacturers of HV equipment, together with producers and distributors of electrical power, have a growing interest in on-site, off-line and on-line analysis of PD in existing HV components. The objective of such analysis is the early recognition and location of possible insulation failures in $\mathrm{HV}$ equipment. As a result, maintenance actions can be planned to prevent unexpected interruptions in equipment utilization. Furthermore, based on knowledge of the type of discharge and its behavior over time, important information can be obtained regarding degradation processes.

The ability of digital PD analyzers to process and store specific information concerning discharge activity can be used for various purposes: discharge recognition, condition monitoring, etc. [1-15]. To exploit these possibilities, a specific fingerprint technique has been successfully used in recent years for off-line and on-line PD measurements of HV components $[12,16-18]$.

In this paper diverse practical examples are discussed of applying advanced digital post-processing for the measurement of partial discharges.

\section{PD Database for Decision Support}

The development of a PD database to support the discharge evaluation during periodic off-line inspections of $\mathrm{HV}$ components is of great importance. In this paper, based on PD measurements of various HV components, the importance of digital analysis of PD signals and the development of PD databases to

\section{Edward Gulski and Johan J. Smit}

High Voltage Laboratory, Delft University of Technology, The Netherlands

\section{Roger Brooks and Mark Turner}

Tettex Instruments Division, Haefely Trench AG, Switzerland

Digital PD processing provides several quantities to evaluate discharges in $H V$ equipment.

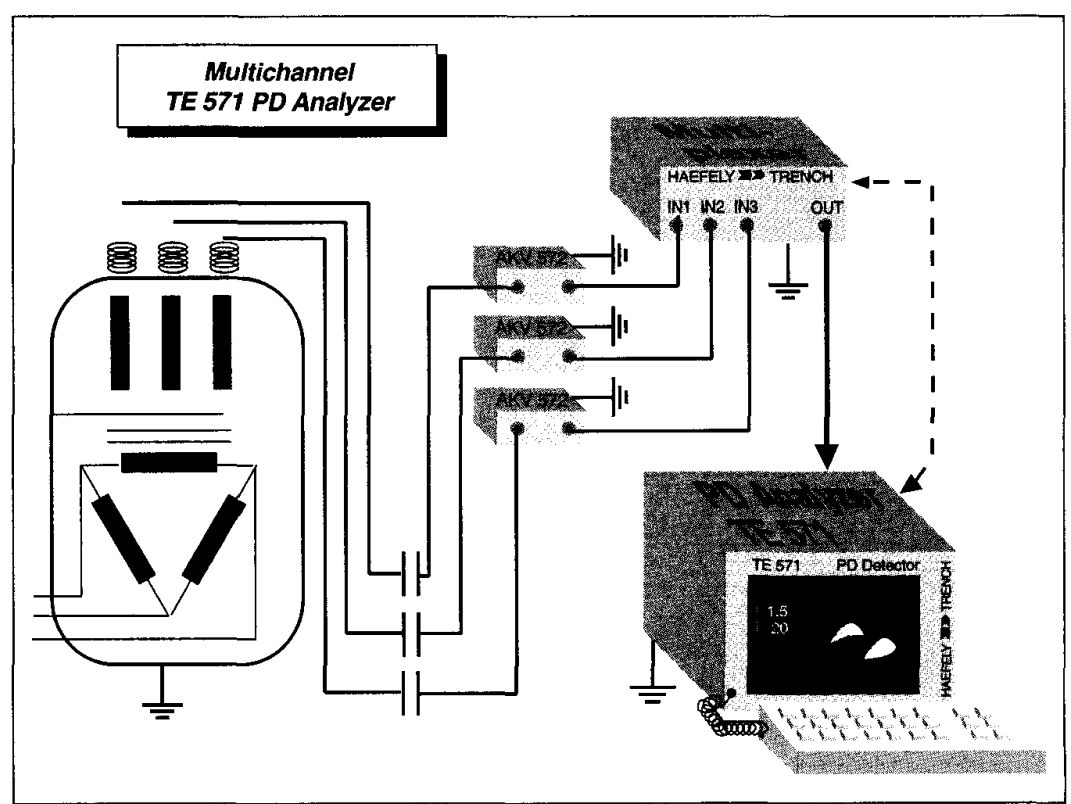

Fig. 1 Schematic diagram of a transformer test circuit using a multichannel digital PD analyzer 


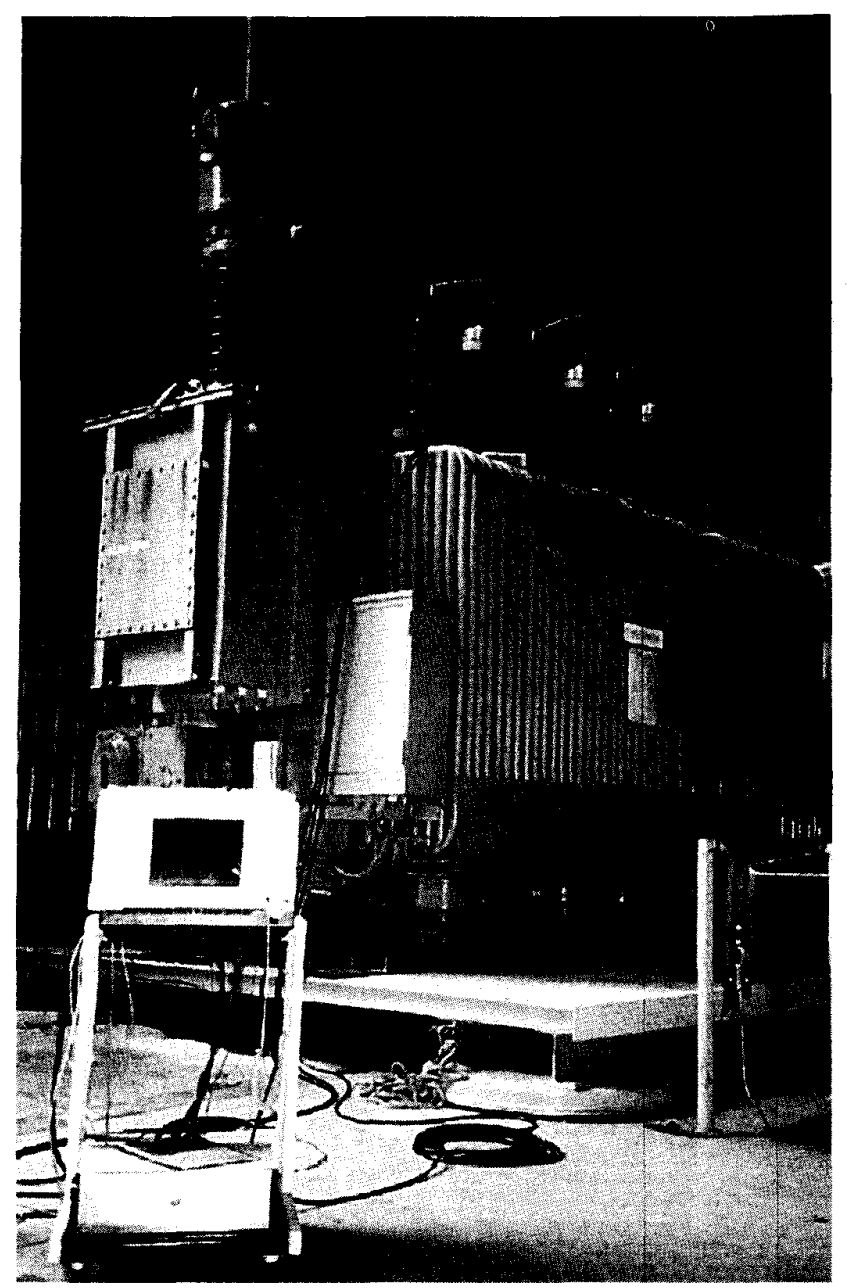

Fig. 2 PD diagnostic test on a $50 / 10 \mathrm{kV}, 14 / 10$ MVA power transformer using a digital PD analyzer (HVLaboratory, TUDelft, The Netherlands)

support the discharge evaluation during periodic off-line and on-line inspections of $\mathrm{HV}$ components will be discussed.

It is known that important conclusions are made regarding the condition of the test object insulation based on periodic off-line PD measurements. It is also known that several types of $\mathrm{HV}$ apparatus are not discharge free. On the contrary, a certain level of discharges is often allowed. Furthermore, the interpretation of measurement results often depends on the subjective opinions of test engineers.

With the advance of digital processing, the task of data acquisition and evaluation can now be performed more efficiently. In the last five years several commercial products have been introduced and are in use around the world. Moreover, to support the sharing of experience with regard to recognition, classification, and discrimination of different discharge types, a data standard has been introduced by CIGRE [19].

In the past, a strong relationship has been found between the shape of the (phase resolved) PD patterns that occur in relationship to the power frequency sine wave and the type of defect causing them. From a practical point of view it was

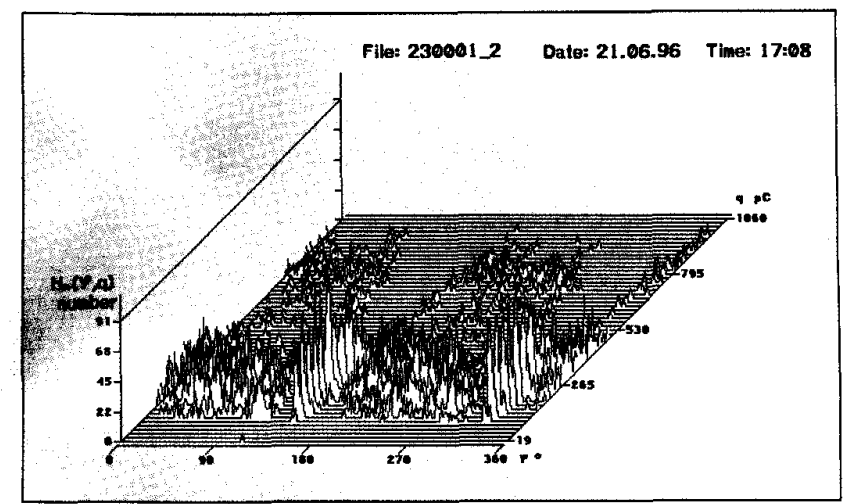

Fig. 3 Regular 3-D discharge pattern $H_{n}(\gamma, q)$ for a 203 MVA transformer in good condition

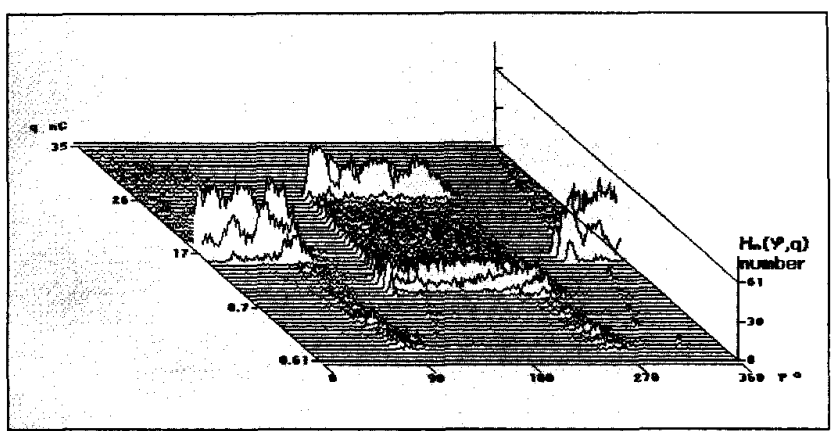

Fig. 4 Irregular 3-D discharge pattern $H_{n}(\gamma, q)$ observed for a $55 \mathrm{MVA}$ reactor exhibiting $P D$ on a damaged screen inside the test object

shown that two types of PD patterns are of particular interest for interpreting PD measurements:

Regular PD patterns: which are characteristic of a particular type of HV component with insulation in good condition (see Figs. 3 and 8);

Irregular PD patterns: representing certain unacceptable discharge sources. These may be related to manufacturing defects or to the effects of ageing during service life (see Figs. 4 and 9).

This study describes PD databases created for two main areas of application: induced voltage tests of power transformers and reactors (based on measurements of 80 different units), and off-line PD measurements of turbogenerators (based on measurements made over the last two years on 20 different units with ratings of $6 \mathrm{MW}$ and $63 \mathrm{MW}$ ). In both cases the PD analysis system described in [16-18] was used.

\section{PD Database for Power Transformers and Reactors}

When a measurement has been made on a test object (see Figs. 1-2) it can be compared with a PD database comprising a collection of previous PD tests. For reasons of clarity, the PD database has been divided into two separate parts. The first part consists of measurements made on reactors, whereas the second part concerns only auto-transformers and three-phase transformers. The main goal of this PD database was to answer questions about general trends in regular or irregular PD 


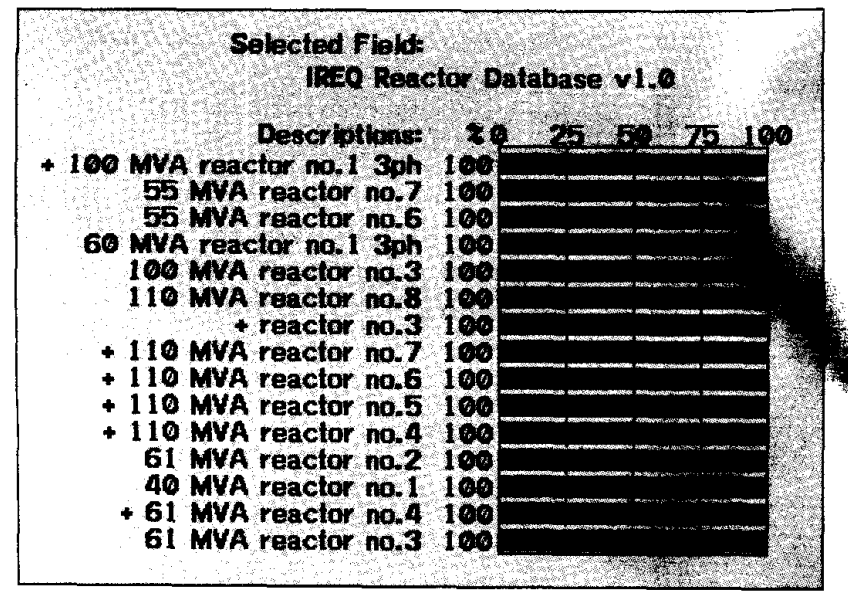

Fig. 5 Computer-aided recognition of regular PD patterns using a PD database for reactors. Typical is the overlap with other reactors also showing regular PD patterns. (+), (-), () represents a test object in the database characterized by a (regular), (irregular), (unknown) pattern, respectively.

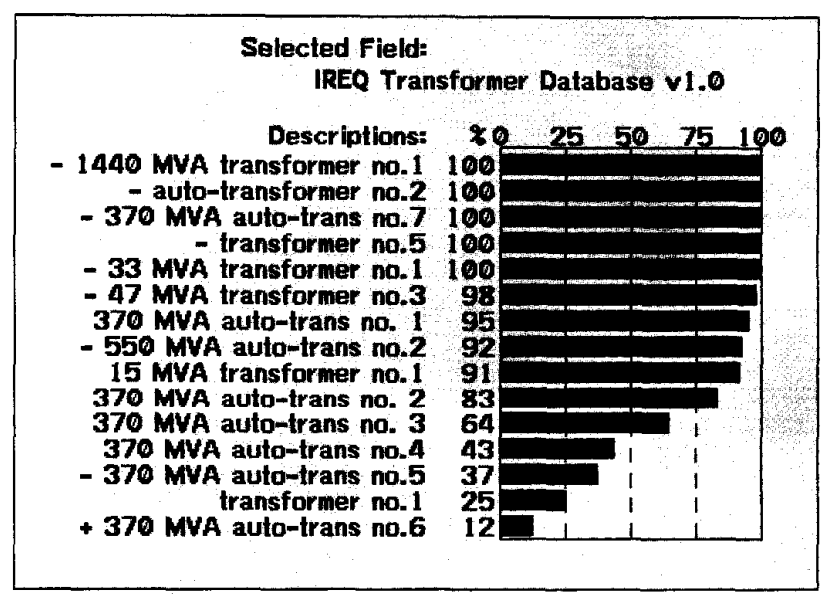

Fig. 6 Computer-aided recognition of irregular $P D$ patterns using a $P D$ database for transformers. Typical is the overlap with other transformers also showing irregular PD patterns. (+), (-), () represent a test object in the database characterized by a (regular), (irregular), (unknown) pattern, respectively.

patterns occurring during induced voltage testing of power transformers and reactors. In the following, two examples are given showing an application of both PD databases during the classification of an unknown measurement. As observed in [10], the classification of an acceptable PD pattern using a database (Fig. 5) often resulted in multiple correlation. In most of these cases a low discharge magnitude and low discharge intensity was observed (+). No correlation was found to unacceptable PD patterns. When a typical defect was classified, correlation was found to only a few patterns (Fig. 6), most of which had shown unacceptable PD.

\section{PD Database for Turbogenerators}

When discharge data are measured during periodic inspections every few years, PD patterns of separate coils can be compared with those observed during previous inspec- tions. Based on this experience, several characteristics have been found to describe typical insulation problems of stator insulation [21]. Several groups of PD patterns have been

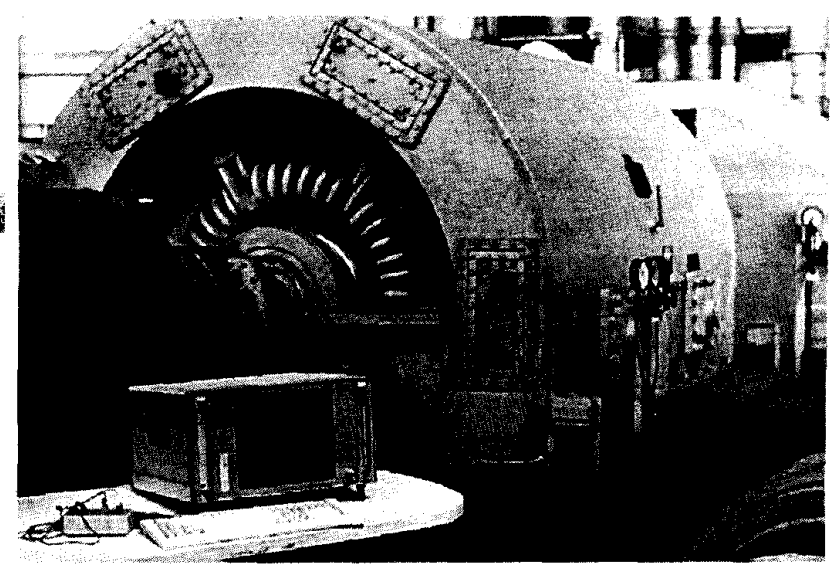

Fig. 7 Off-line periodic PD inspection of a $63 \mathrm{MW}$ turbogenerator using a digital $P D$ analyzer (ABB Dolmel Ltd., Poland)

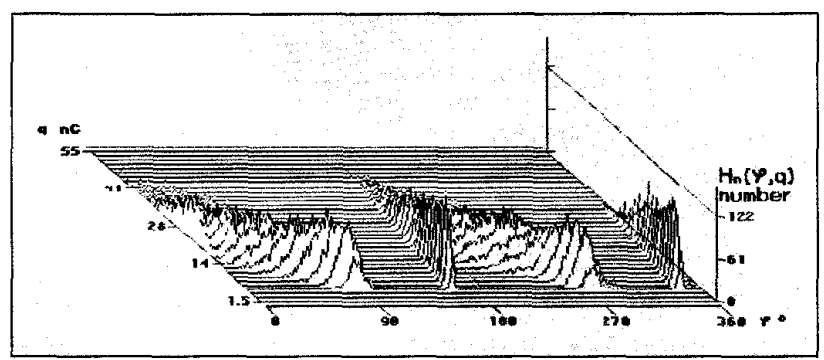

Fig. 8 Example of a regular PD pattern observed in a $63 \mathrm{MW}$ turbogenerator: The outer and inner sinusoidal shapes of the $3 D$ phase-resolved distribution $H_{n}(\gamma, q)$ are typical for turbogenerators in good condition.

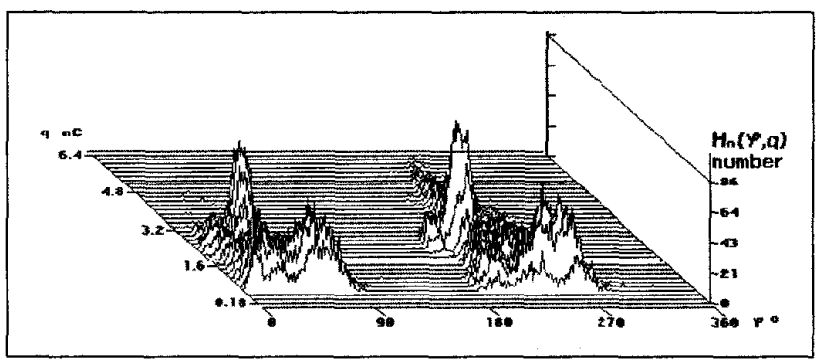

Fig. 9 Example of an irregular PD pattern observed in a $6 \mathrm{MW}$ turbogenerator. This $H_{n}(\gamma, q)$ phase-resolved distribution was observed in the presence of end winding discharges

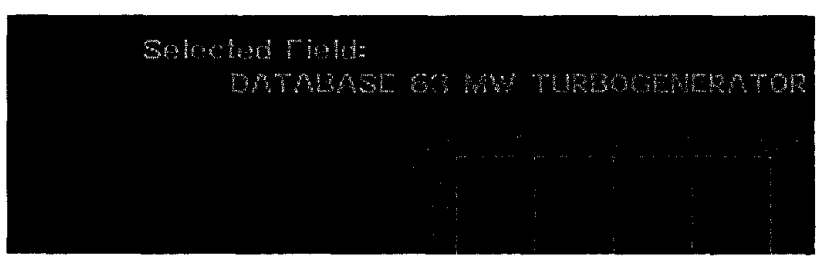

Fig. 10 Example of pattern recognition using the $63 \mathrm{MW}$ turbogenerator database in the case of an irregular PD pattern; the high \% represents classification as slot discharges. 
identified in the case of irregular PD patterns. Based on various inspections and repairs the following discharge sources were found during periodic PD measurements:

a) $\mathrm{PD}$ in the HV bushings,

b) $\mathrm{PD}$ in a slot section caused by damaged outer corona protection,

c) PD in the end winding section.

Such PD patterns were also observed by Stone [22-23]. As a result, two PD databases have been developed to support the recognition of insulation degradation during periodic off-line inspection, one for $6 \mathrm{MW}$ and one for $63 \mathrm{MW}$ units. Figs. 10 and 11 show the classification of a particular defect using these databases. Both examples confirm that the PD

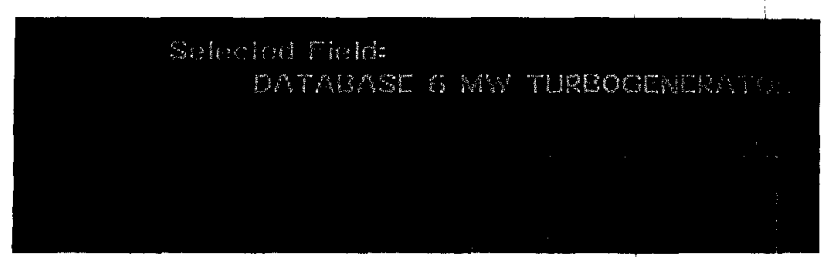

Fig. 11 Example of pattern recognition using the $6 \mathrm{MW}$ turbogenerator database in the case of an irregular PD pattern; the high \% represents classification as end winding discharges.

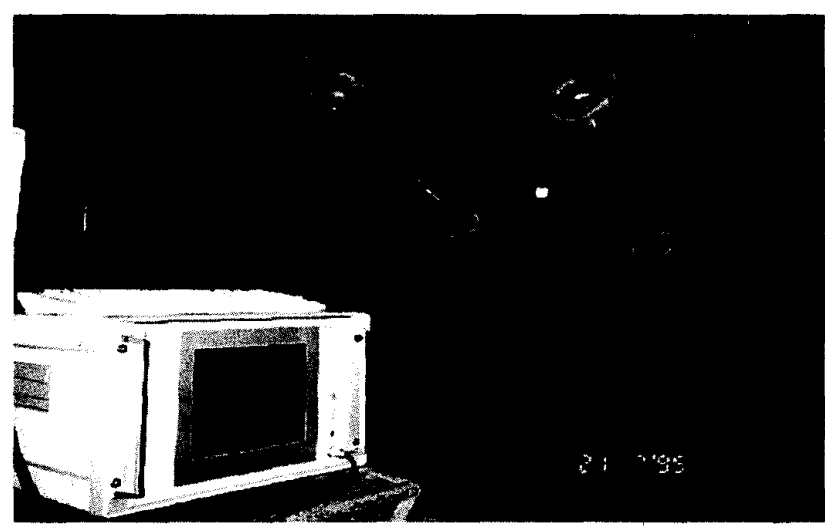

Fig. 12 Digital PD detector for location of defects in HV cables (NKF Kabel B.V. Delft, The Netherlands)

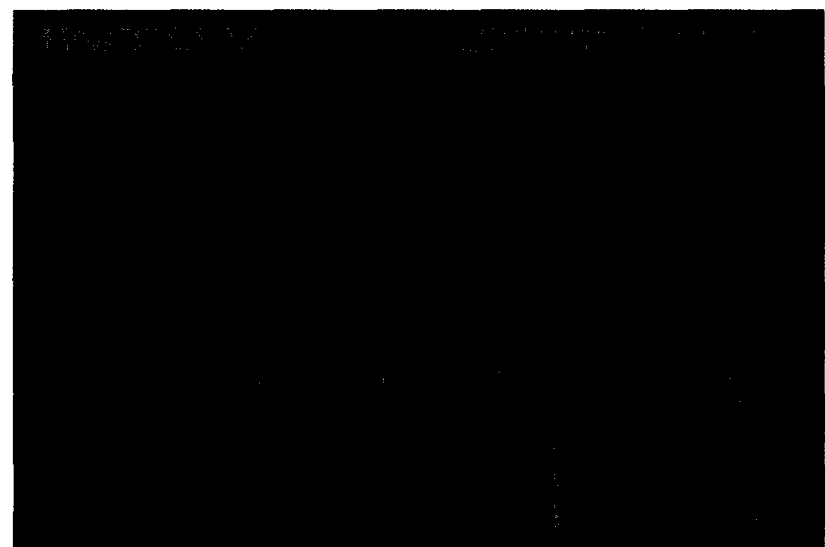

Fig. 13 Indication of discharge site location at $1194 \mathrm{~m}$ in a $1785 \mathrm{~m}$ long, plastic-insulated HV cable patterns measured for particular defects can be used for identification of these defects.

The digital classification of PD patterns observed during periodic PD measurements on HV components has made it possible to develop a decision support database for discharge faults. Two different ways of constructing a PD database have been shown. One provides a distinction between objects in good condition and objects showing unacceptable discharges. The other confirms the possibility of identifying the source of the discharge in the insulation.

It has also been demonstrated in [24] that it is sometimes possible to distinguish between components in good condition and those that show internal or external discharges originating from insulation degradation using this technique.

\section{Digital PD Location in HV Cables Using the Traveling Wave Method}

Partial discharges occur in gas-filled cavities in a dielectric and cause a gradual erosion of the insulation material. For this reason the location of PD in HV cables is important for quality control. Traveling waves are widely used for PD location, as introduced in 1960 by Kreuger [25]. This method

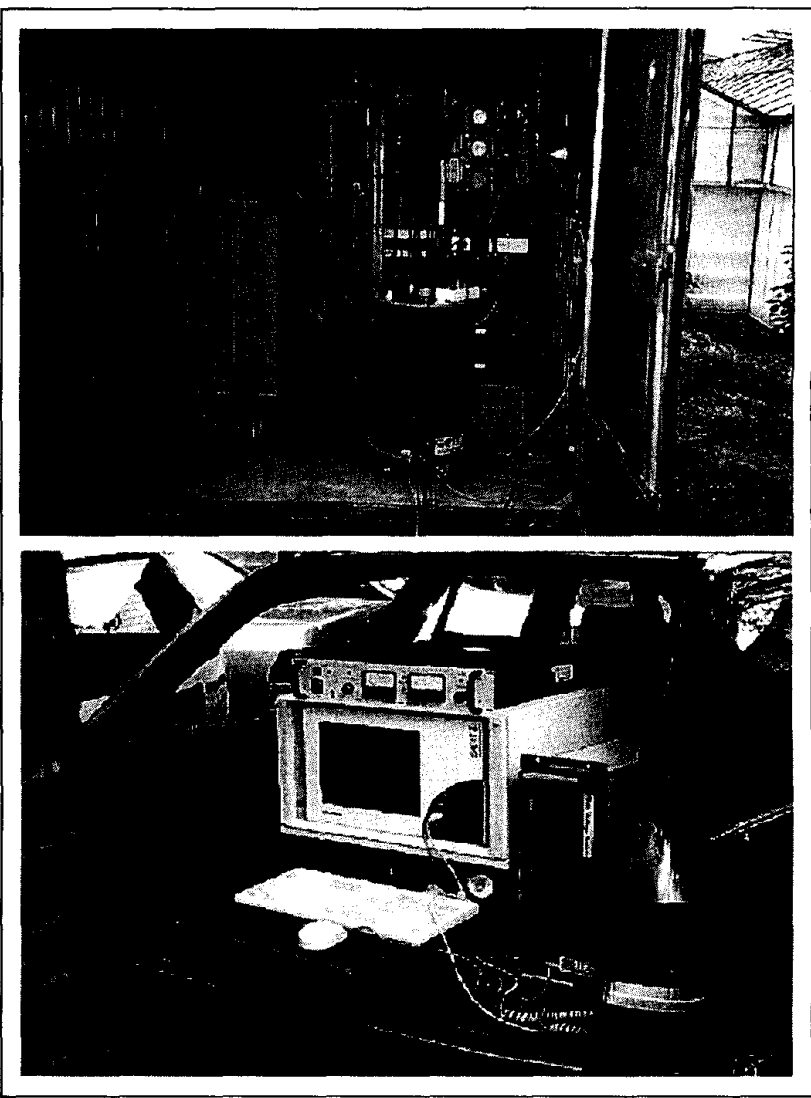

Fig. 14 On-site PD diagnosis of a $3 \mathrm{~km}$ long, $10 \mathrm{kV}$ power cable using a $50 \mathrm{kV}$ oscillating wave test system

Top: unit consisting of low loss air core, $H V$ divider and PD coupling device connected to the cable termination,

Bottom: HV power supply, control and data acquisition unit 
was automated a few years ago and is now widely used in shielded laboratories (see Fig. 14 and [26]).

If $P D$ measurements on power cables have to be performed on site, different solutions are needed [27-31]. One proposed recently is based on nondestructive PD measurements using oscillating waves [32]. This method is used to energize, measure, and locate partial discharges in power cables on site, in accordance with IEC 60270 recommendations.

The oscillating wave test system consists of a digitally controlled flexible power supply to charge long cable lengths for resonant excitation at power frequencies of a few hundreds of $\mathrm{Hz}$ and a fast digital recording and statistical evaluation system for discharges (see Fig. 14). In this method, the cable sample is charged with a dc power supply over a period of just a few seconds to the usual service voltage. Then a specially designed solid state switch connects an air-core inductor to the cable sample in a closure time of $<1 \mu \mathrm{s}$. Then the circuit oscillates through a series of voltage cycles at its resonant frequency: $f=1 /(2 \pi \bullet \sqrt{\mathrm{L}} \bullet \mathrm{C})$ where $\mathrm{L}$ represents the fixed inductance of the air core and $C$ represents the capacitance of the cable sample. The air-core inductor has a low loss factor and is designed so that the resonant frequency lies in the range immediately above the power frequency of the service voltage: $50 \mathrm{~Hz}$ to $1 \mathrm{kHz}$.

Specifically, this compact, lightweight solution is used to generate HV oscillating waves with a duration of a few tens of cycles of ac voltage at frequencies up to a few hundreds of $\mathrm{Hz}$. The analysis of PD in power cables using this technique represents a new advance in the adaptation of the latest digital technology for $\mathrm{HV}$ insulation diagnosis.

\section{Recognition of Defects in GIS}

Acceptance tests and periodic off-line measurements of $\mathrm{SF}_{6}$ gas-insulated test objects are restricted to the measurement of PD inception voltage (in $\mathrm{kV}$ ) and maximum discharge magnitude in $\mathrm{pC}$ and comparing these with the test specifications. The test objects may be GIS substations or GIS components such as switchgear, disconnectors, and bus bars. If the permitted PD level is exceeded, then the main goal of evaluation in GIS is to localize the discharge source. For periodic inspection, it is also possible to use VHF/UHF sensors to measure PD signals on-line [33-34]. The VHF/UHF detection circuit usually consists of a sensor and a spectrum analyzer (see Fig. 16 and [35-36]).

The main objective of a PD measurement, whether it is based on IEC 60270 or $\mathrm{VHF} / \mathrm{UHF}$, is to assist with the recognition and location of the discharging defect. To support the evaluation process during a measurement it is possible to use reference PD patterns of typical defects. Some examples of typical GIS defects are described below.

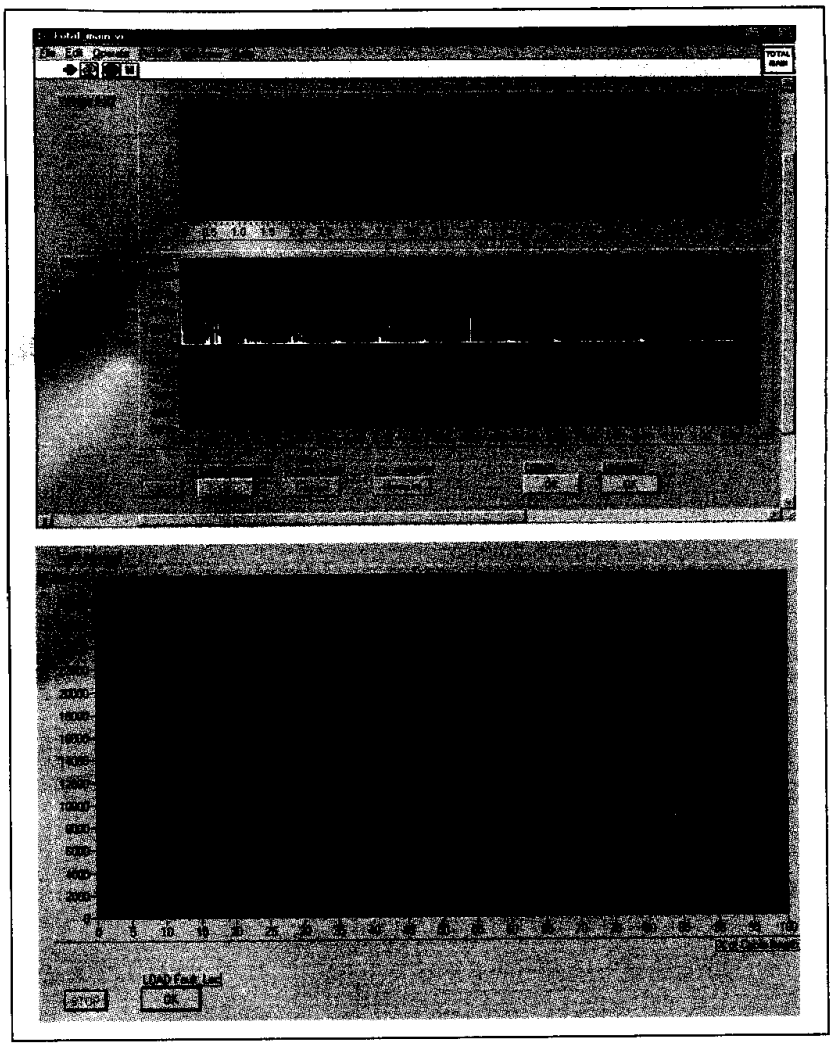

Fig. 15 On-site PD analysis of medium voltage power cables using the oscillating wave test method

Top: measurement display showing internal discharges after applying a $12 \mathrm{kV}$ oscillating wave to a $12 \mathrm{kVXLPE}$ power cable Bottom: display of statistical evaluation obtained after three $12 \mathrm{kV}$ oscillating waves applied to a $12 \mathrm{kV}$ paper-oil cable; location of PD in a joint

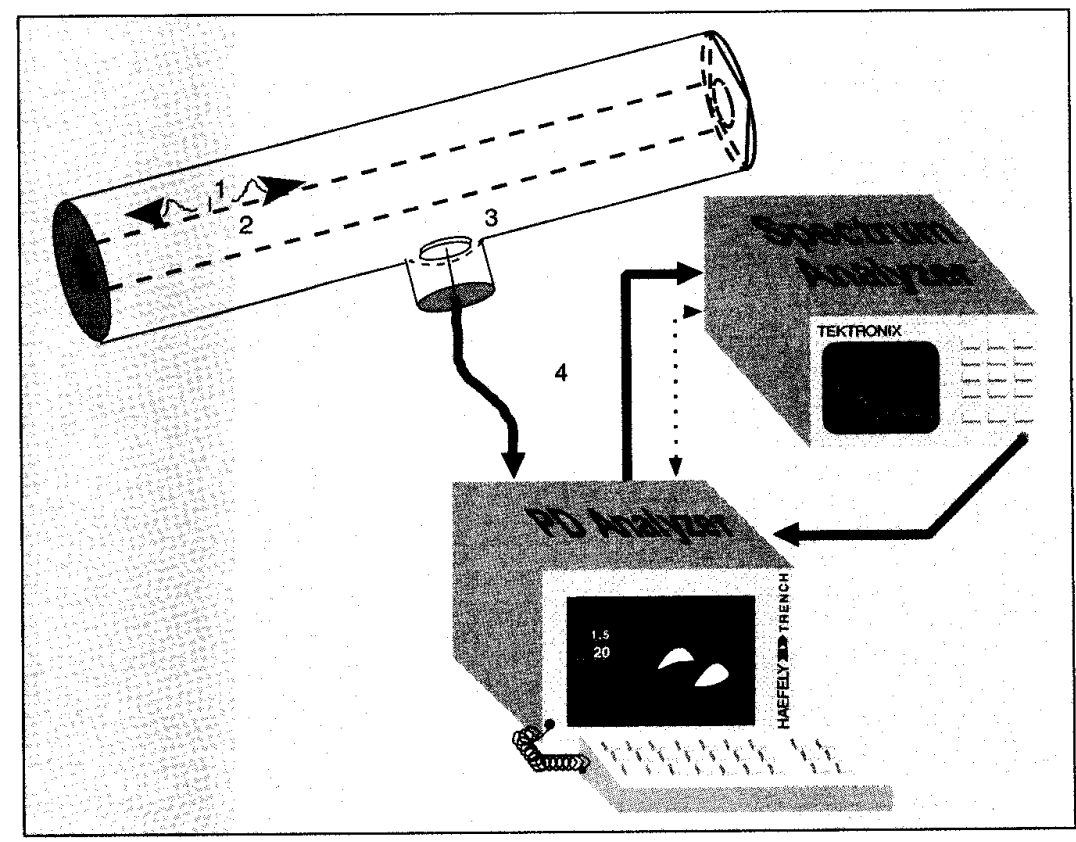

Fig. 16 Four important components to VHF/UHF PD measurements in GIS: (1) Dis charging defect, (2) Excitation of traveling waves, (3) Transfer function sensor, (4) Data processing 


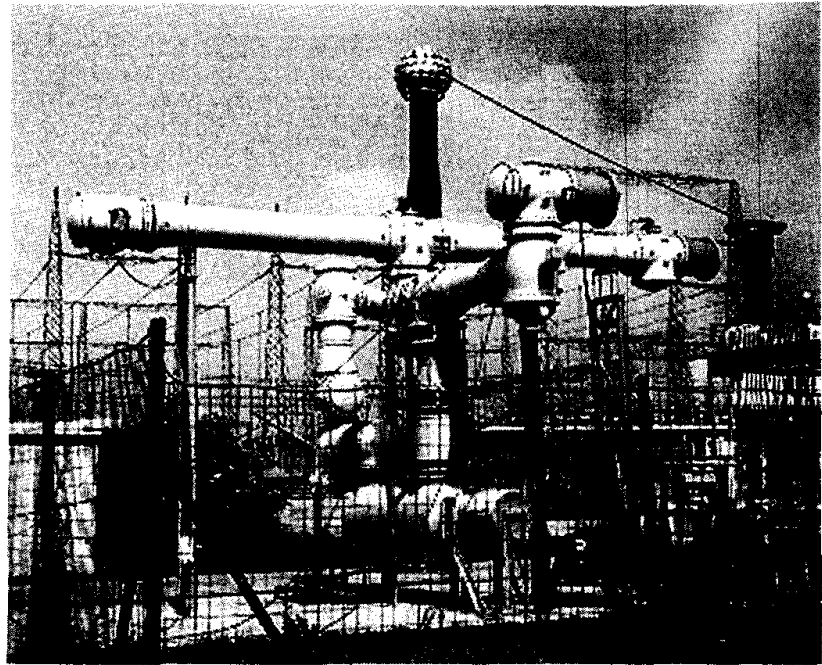

Fig. 17420 kV GIS test setup

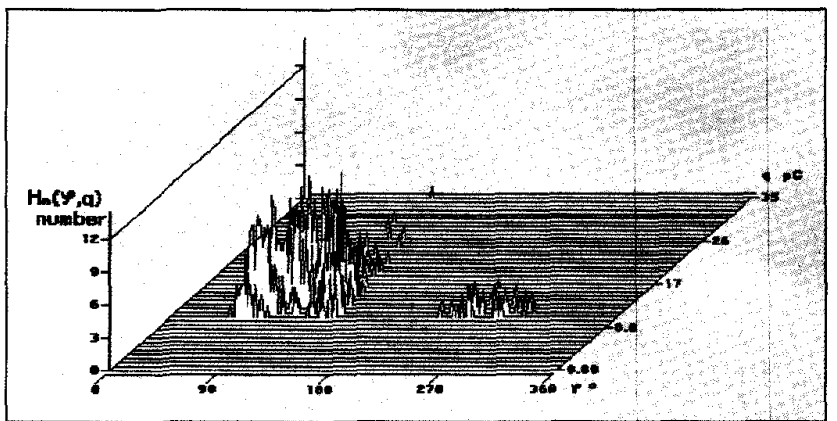

Fig. 18 Protrusion on the conductor at $220 \mathrm{kV}$

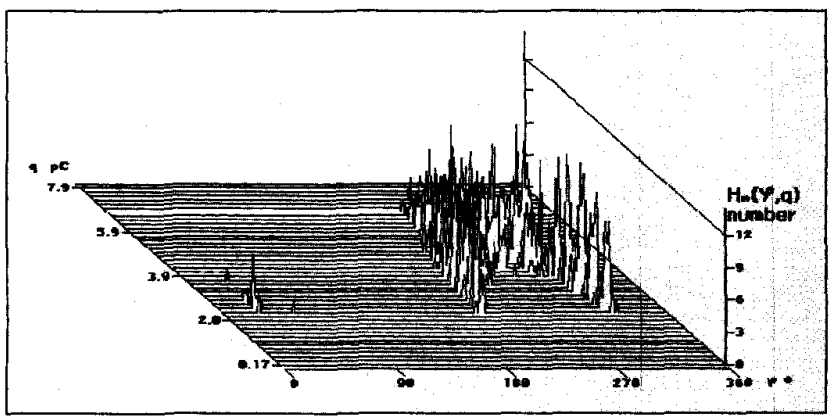

Fig. 19 Protrusion on the enclosure at $90 \mathrm{kV}$

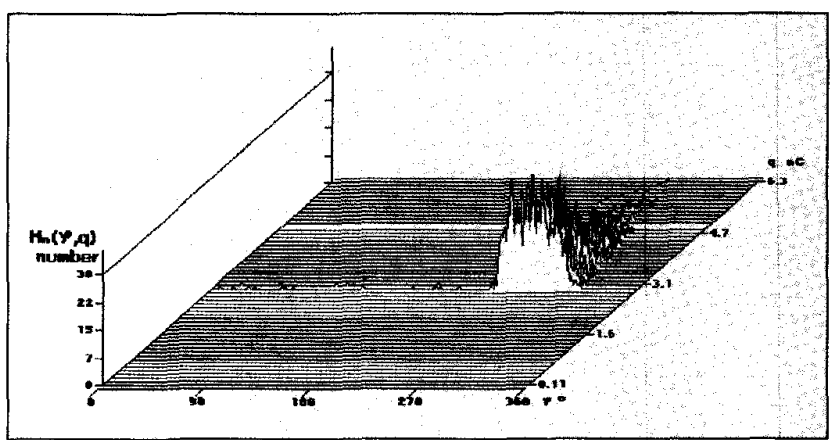

Fig. 20 Particle on insulator at $294 \mathrm{kV}$
Protrusion on the HV conductor represents sharp conducting particles that may occur on the HV electrode inside the GIS installation. Fig. 18 shows a typical phase-resolved plot.

Protrusion on the enclosure represents sharp conducting particles on the surface of the enclosure. Fig. 19 shows a phase-resolved plot. It follows from this comparison that the asymmetry between discharges in the positive and negative half of the applied ac voltage in case of a protrusion on the enclosure and a protrusion on the conductor is typical for both defects.

A particle on an insulator means a small conducting particle is contacting the surface of an insulator (spacer) and is distorting the field by producing a local field concentration. As a result, the breakdown voltage along the surface is diminished and in some cases discharges may occur before the breakdown occurs. Fig. 20 shows a phase-resolved plot.

A free-moving particle inside the enclosure means a conducting particle that is not fixed to any of the electrodes or insulators and may move (jump) inside the enclosure with a certain frequency. As a result, PD occurs, producing patterns as shown in Fig. 21. In contrast to the three defects mentioned above, a typical sinusoidal shape can be observed in the phase-resolved plot for this defect.

Internal defect in the moving parts: Circuit breakers and disconnectors are mechanically and electrically stressed during their service life. As a result, ageing processes occur inside the elements. An example of internal discharges in the grading capacitances of switchgear is shown in Fig. 23.

Foreign particles and ageing processes of solid materials are not the only contributors to GIS failures. Floating parts in the installation, i.e., electrodes imperfectly connected to HV potential, may cause regularly repeating discharge

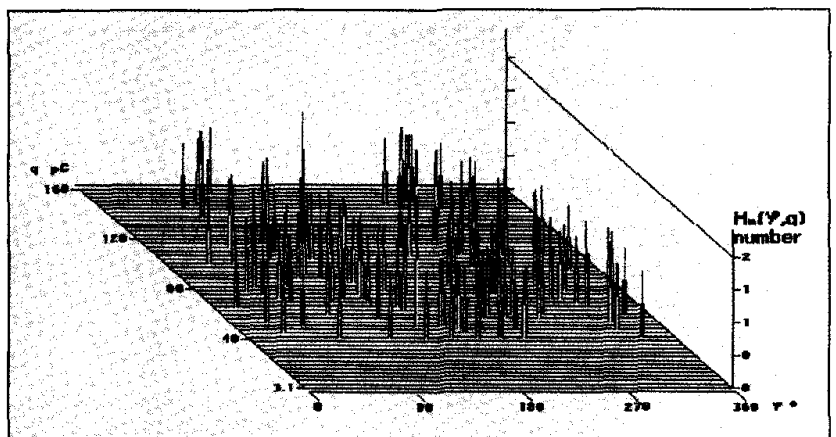

Fig. 21 Free-moving particle at $261 \mathrm{kV}$

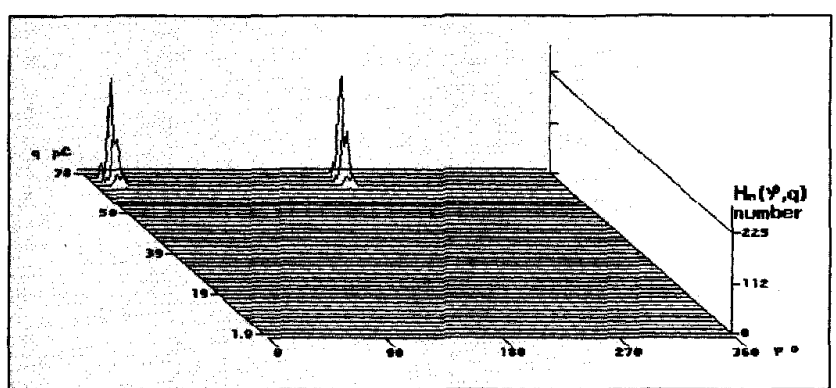

Fig. 22 Floating electrode in 4 bar $S F_{6}$ 
groups of the same amplitude (see Fig. 22). This pattern confirms the observation made before that each of the GIS defects is characterized by its own PD pattern. PD quantities processed by a digital PD analyzer [16-18] can provide further information for evaluation and diagnosis of PD measurements in GIS.

The systematic approach of examining digitally acquired PD quantities lays the foundation for a more systematic analysis of the different digital techniques and statistical tools that are in use in the field of recognition and diagnosis of discharges in GIS components.

Fig. 24 shows an example of statistical analysis using digital tools applied to four different PD fault patterns: a protrusion on the conductor, a protrusion on the enclosure, free-moving particles, and a particle fixed to an insulator. Recognition, discrimination, and classification of these faults are shown to be possible using digital tools.

\section{PD Pattern Analysis of On-Line Measurements on Rotating Machines}

In addition to periodic off-line PD testing, on-line PD measurement is an accepted method for rotating machines [23]. Using experience gained from off-line PD tests, this method can be utilized for condition-based monitoring of the stator insulation [37-40].

The PD signals are measured by a specially adapted digital PD detector (Figs. 25 and 26) using capacitive or inductive couplers while the generator is in regular operation. The couplers are permanently installed on the generator (at least one on each phase) and an on-line test can then be performed. This type of measurement is easily performed without interrupting the operation of the generator. As a result, the PD measurement is taken on a sample under operational thermal and mechanical stresses. Two difficulties arise when such PD measurements are needed:

- system interference may occur in the measuring circuit due to the power plant or from rotor excitation;

- complex propagation of PD signals through the stator winding occurs, resulting in cross-talk. This is due to the fact that all three phases are energized at the same time.

A spectrum analyzer (SA) can be used as a tuned filter to suppress external noise. The $\mathrm{SA}$ is tuned to a frequency in the range of 10 $\mathrm{MHz}-100 \mathrm{MHz}$ where PD from the stator insulation dominates the noise signals (see Fig. 27). This measurement method is known as the VHF PD detection technique due to the frequency range involved. The level of PD signals at the selected center frequency $\mathrm{f}_{0}$ is demodulated to some hundreds of $\mathrm{kHz}$ and displayed on a $50 \mathrm{~Hz}$ time base. As a result, the measured signals can be further processed by a conventional PD analyzer with

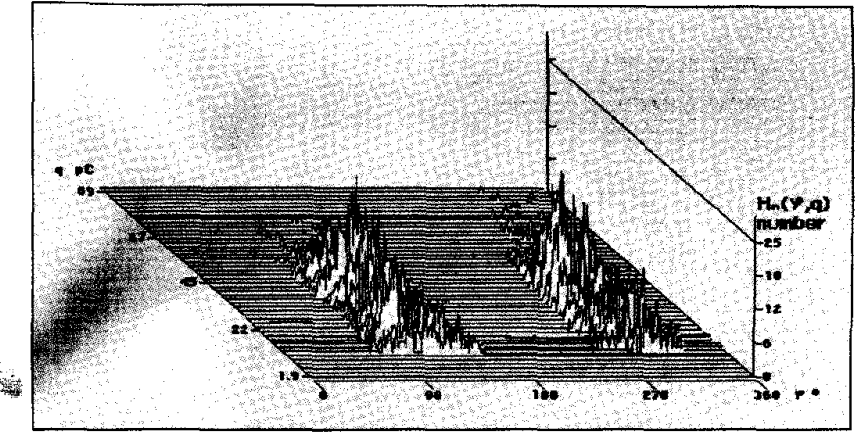

Fig. 23 Internal fault in switchgear at $138 \mathrm{kV}$

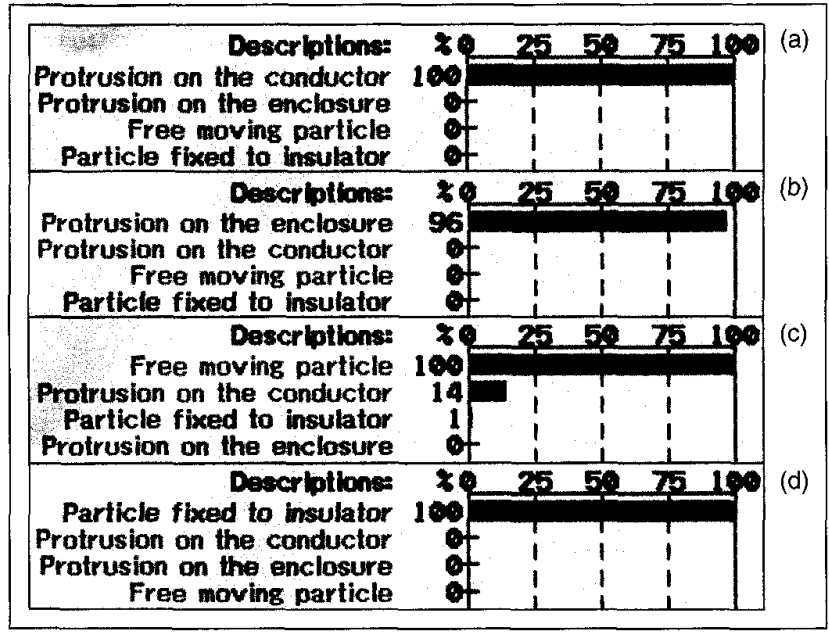

Fig. 24 Statistical analysis according to [12, 16-18] applied to four different PD patterns: (a) protrusion on the conductor, (b) protrusion on the enclosure, (c) free moving particle, (d) particle fixed to an insulator 


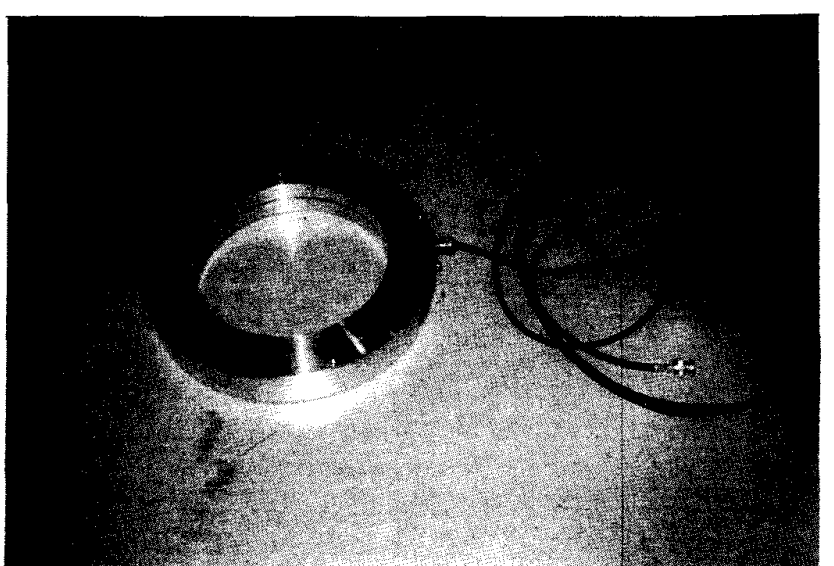

Fig. 26 VHF PD coupler for TE 571 PD analyzer (see Fig. 25): type: split ring Rogowski coil, $160 \mathrm{~mm}$ dia., terminating impedance: 50 , bandwidth: 5-100 MHz, sensitivity: $96 \mathrm{mV} / \mathrm{A}$

the goal of applying the broader experience of phase resolved PD pattern recognition [41-42].

\section{Partial Discharge Patterns}

As mentioned above, the measured PD patterns will reveal the single-phase $\mathrm{PD}$ response together with $\mathrm{PD}$ responses from the other phases due to the effect known as cross-talk. The position of the single-phase patterns with respect to the power cycle of phase U is illustrated in Fig. 28, showing the $120^{\circ}$ shift between the phases.

The selection of a suitable resonant frequency for measurement is an exceptionally delicate procedure. This is illustrated in Fig. 29, which shows five PD patterns measured on the same phase of a generator at different resonant frequencies. At $\mathrm{f}_{0}=18 \mathrm{MHz}$ the PD pattern is that of the measured phase. At $\mathrm{f}_{0}=30 \mathrm{MHz}$ and $\mathrm{f}_{0}=62 \mathrm{MHz}$ the PD pattern observed is that of the measured phase together with cross-talk. No response at all is measured at $\mathrm{f}_{0}=48 \mathrm{MHz}$ and at $\mathrm{f}_{0}=64$ $\mathrm{MHz}$ only cross-talk is measured.

The results of on-line measurements performed on a 155 MW and a $650 \mathrm{MW}$ turbogenerator clearly illustrate this influence of the center frequency chosen on the following responses (see Fig. 30):

- the PD response of the measured phase, i.e., the PD activity originating from that phase;

- the cross-talk PD response, i.e., the PD activity originating from the other phases;

- the disturbance response, i.e., disturbances originating from the power plant and from the generator itself (e.g., rotor excitation).

\section{Evaluation for Condition Monitoring}

When a suitable frequency is found and selected for the measurement of the phase's own PD pattern, the pattern's characteristics can be used for identification of the insulation state. Experience resulting from analysis of off-line PD tests can be used to assist in the interpretation of PD patterns.

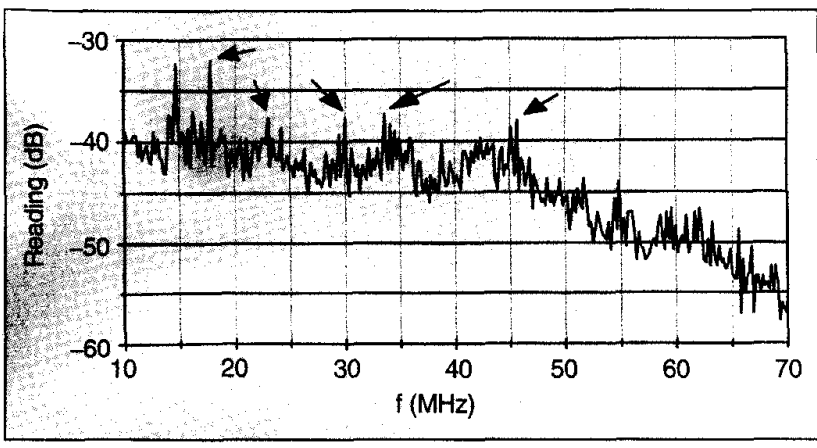

Fig. 27 Example of FS as obtained with the SA. The peaks at frequencies marked by the arrows indicate response above the noise level at these values of $f_{0}$

For example, Fig. 30 shows the three-dimensional $\operatorname{Hn}(\gamma, q)$ distribution of a measurement on phase $U$ of a $155 \mathrm{MW}$ turbogenerator. The measurement was performed at $\mathrm{f}_{0}=53$ $\mathrm{MHz}$. The pattern shows the phase's own PD, PD cross-talk and disturbances. The phase's own PD pattern shows the characteristics of a regular PD pattern of insulation with no significant degradation [11].

Several conclusions can be drawn, based on experience gained from the on-line technique for PD tests presented above.

On-line VHF detection of PD processes in the insulation of a generator phase can be performed with a number of suitable SA center frequencies.

Careful selection of center frequencies can provide information about the insulation condition of the phases of a generator by analysis of the PD patterns. It can be expected that, in the course of time, local insulation degradation and disturbances will be identifiable by the PD pattern deviation.

\section{Conclusions and Suggestions}

It has been shown in practical cases that a digital PD system provides additional information, can support the documentation and analysis of a PD measurement, can help to

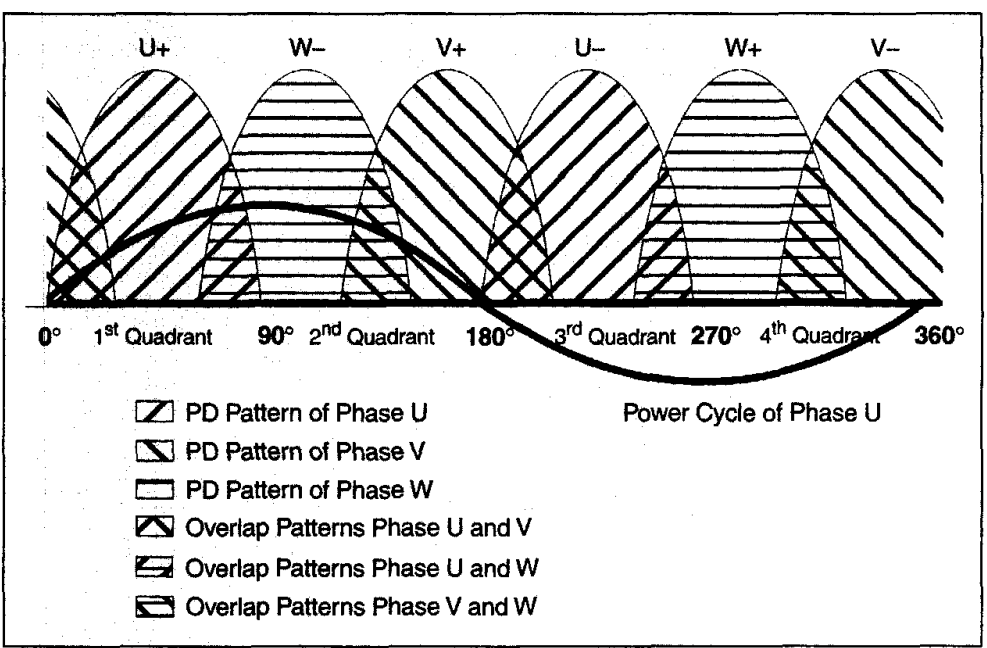

Fig. 28 Positions of the single-phase patterns with respect to the power cycle of phase $U$ 


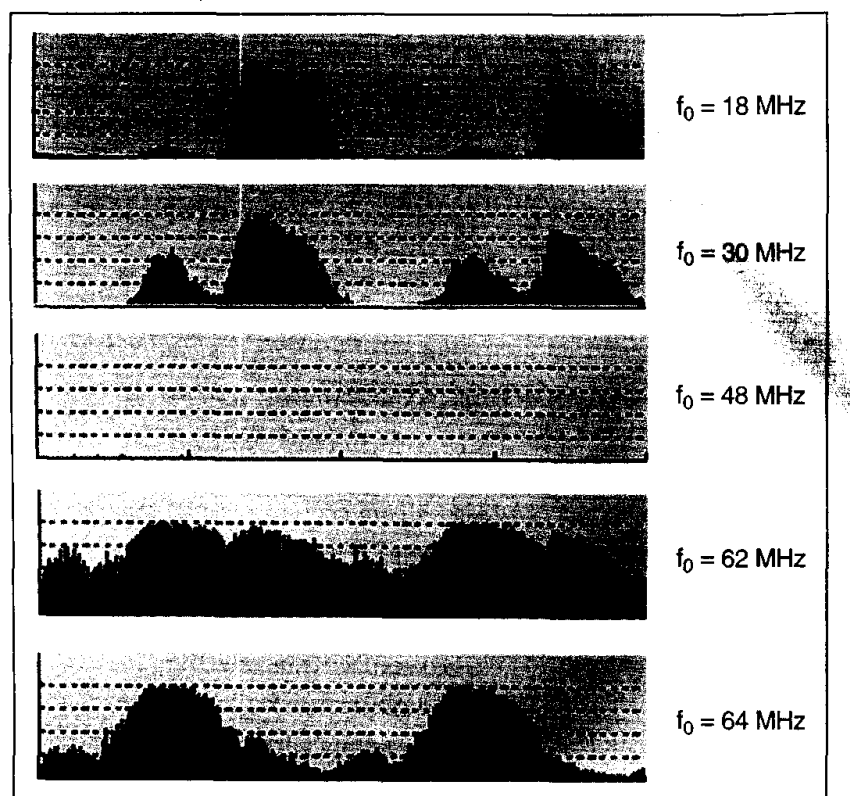

Fig. 29 Demonstration of the influence of $f_{0}$. Measurement at different $f_{0}$ on phase $\mathrm{W}$ of a $650 \mathrm{MW}$ generator produces different patterns.

inventory and evaluate different measurements, but is no $100 \%$ substitute for our experience. In particular the following have been shown:

A) Digital PD processing provides several quantities to evaluate discharges in $\mathrm{HV}$ equipment.

B) A PD database is an important tool for recognizing different defects and analyzing changes in the insulation.

C) The combination of PD quantities, database application and classification tools can be applied to PD diagnosis of power transformers, HV cables, generators and GIS.

The discussion of this paper could lay the foundation for a more systematic analysis of the different digital techniques and statistical tools that are in use in the field of recognition and diagnosis of discharges in HV components.

Edward Gulski was born in 1958 in Poland. In 1982 he received from Dresden University of Technology in Germany the M.S. degree in information technology. From 1982 until 1986 he worked as research assistant at the HV laboratory of Dresden University of Technology. In 1987 he joined the HV laboratory of the Delft University of Technology in The Netherlands where he performed research in the field of partial discharge diagnostic. In 1991 he received the Ph.D. degree from Delft University of Technology. At present he is associate professor at Delft University involved in education and research in the field of insulation diagnostics of HV components. He is a member of different CIGRE working groups and task forces.

Johan J. Smit was born in 1949 in The Netherlands. After receiving his master's degree in 1974 in experimental physics at the University of Amsterdam he received his Ph.D. at the State University of Leiden in 1979 for his research in magnetism on behalf of the National Science Foundation. Next he was employed for 17 years at KEMA in Arnhem, where he became section manager within the transmission and distribution company. Since

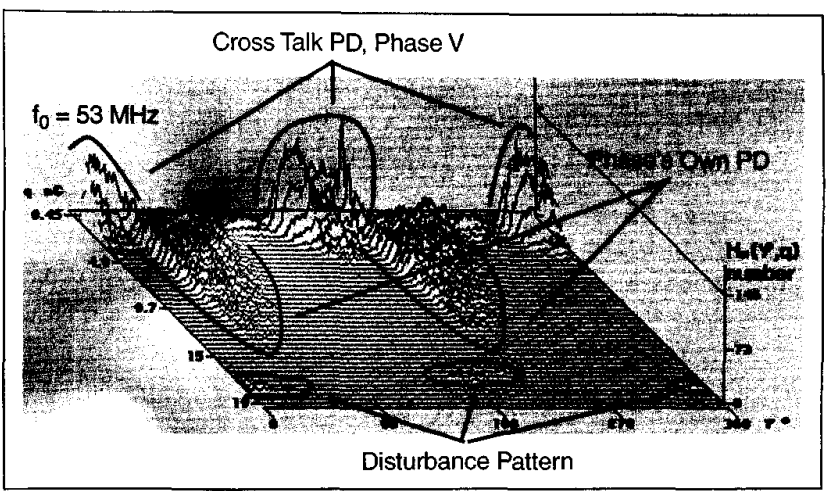

Fig. $30 H_{n}(\gamma, q)$ distribution as measured on phase U of a $155 \mathrm{MW}$ turbogenerator at $f_{0}=53 \mathrm{MHz}$. The pattern shows a regular shape for phase-own PD patterns (no degradation), as well as cross-talk and disturbances.

1996 he has been a professor in high voltage technology at the Delft University of Technology. Currently his specific areas of interest are dc and ac HV materials, advanced diagnostics, and maintenance support systems. He is a member of the Technical Committee of IEC 98 on Electrical Insulation Systems. In 1993 he became secretary of CIGRE Study Committee 15, Materials for Electrotechnology, of which he is now chairman.

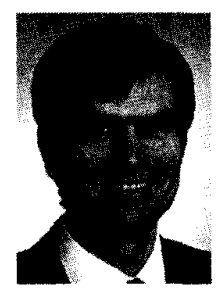

Roger Brooks studied computer science at Northeastern University in Boston, Mass. And New York University and began working as an electronics engineer at Sensormatic Electronics in Florida in 1977, where his work ranged from low-frequency magnetics to microwave electronics. He was registered as a professional engineer in Washington, DC in 1984 on the basis of self-study, never having completed a degree program in engineering. He subsequently worked as a test engineer at DEC's disk drive division in Colorado Springs, 1984-87, and directed the engineering department at Boca Research from 1989 to 1992 , when he moved to Switzerland with his wife, who is Swiss. In 1998 he was awarded senior membership in the IEEE. He recently left his post of four years as manager of engineering at Haefely Trench, Tettex Inst. Division, to lead the software development group at Loewenfels Partner in Lucerne.

\section{References}

1. R. Bartnikas, "A Simple Pulse-Height Analyzer for PD Measurements," IEEE Trans. Instrumentation and Measurement, Vol. IM-18, No. 4, Dez. 1969, pp. 341-345. A.

2. H. G. Kranz, "Rechnerische Untersuchung des Ein- und Aussetzverhaltens von TE bei Wechselspannung," ETZ-A, Bd. 94, 1973, H. 3, pp. 175-177.

3. R. Bartnikas, "Corona Pulse Probability Density Function Measurements on Primary Distribution Power Cables," IEEE Trans. on Power Apparatus and Systems, Vol. PAS-94 No. 3, May/June 1975, pp. 716-723.

4. J. Austin, R.E. James, "On-line Digital Computer System for Measurement of Partial Discharges in Insulation Structures," IEEE Trans. EI, Vol. EI-11, 1976, pp. 129-139.

5. F. Rochon, R. Malewski, G. Vaillancourt, "Acquisition and Processing of PD Measurement During Power Transformer Testing," Conf. on Dielec. Phenomena, Claymont, USA, 1984, pp. 546-554. 
6. R. Haller, E. Gulski, "Automatisierte Erfassung und Verarbeitung von TE-Signalen," Elektrie 38, 1984, H. 10, pp. 383-385.

7. G. Vaillancourt, R. Malewski, D. Train, "Comparison of Three Techniques of PD Measurement in Power Transformers," IEEE Trans. Power Apparatus and System, Vol. PAS-104, No. 4, April 1985, pp. 900-909.

8. T. Okamoto, T. Tanaka, "Prediction of Treeing Breakdown from Pulse Height of PD in Voltage-Phase Angle,"Jpn. J. Appl. Phys., Vol. 24, 1985, pp. 156-160.

9. T. Okamoto, T. Tanaka, "Prediction of Treeing Breakdown from Pulse Height of Partial Discharges in Voltage-Phase Angle," JJAP, Vol. 24, No. 2, Feb. 1985, pp. 156-160.

10. T. Okamoto, T. Tanaka, "Novel PD-Measurement Computer-Aided Measurement System," IEEE Trans. Electrical Insulation, Vol. E1-21, No. 6, December 1986.

11. R. Krump, Ein stoerresistentes Verfahren zur computergesttzten TE-diagnostik in $\mathrm{SF}_{6}$ Schaltanalgen, thesis, Wuppertal University, 1989.

12. E. Gulski, "Computer-Aided Recognition of Partial Discharges Using Statistical Tools," thesis, Delft University of Technology, 1991.

13. G.C. Stone, "Practical Techniques for Measuring PD in Operating Equipment," Proc. of the 3rd Int. Conf. on Diel. Materials, Tokyo, July 8-12, 1991, pp. 12-17.

14. M. Cacciari, A. Contin, G. Rabach, G.C. Montanari, "Diagnosis of Practical Insulation Systems by PD Measurements in the Presence of Multi-Discharge Phenomena," CEIDP, Pocono, USA, 1993.

15. A. Contin, E. Gulski, M. Cacciari, G.C. Montanari, "Inference of PD in Electrical Insulation by Charge-Height Probability Distribution," IEEE Trans. on D and EI, Vol. 5, No. 1, February 1998, 110-117.

16. E. Gulski, P.N. Seitz, "Computer-Aided Registration and Analysis of PD in HV Equipment," 8th ISH, Yokohama, Japan, 1993.

17. E. Gulski, R. Oehler, "New Generation of Computer-Aided PD Measurements," 9th ISH, Graz, Austria, 1995.

18. E. Gulski, "Digital Analysis of PD," IEEE Trans. on D and EI, Vol. 2, pp. 822-837, 1995.

19. CIGRE Data Format for GIS Partial Discharge Software Applications, CIGRE TF 15.03.08, WG 15.03, Electra, No. 177, April 1998.

20. E. Gulski, H.P. Burger, G.H. Vaillancourt, and R. Brooks, "PD Database for Power Transformers and Reactors," 10th ISH, Montreal, Canada, 1997.

21. A. Zielonka, E. Gulski, and K. Andrzejewski, "Application of Digital PD Measuring Techniques for the Diagnosis of HV Generator Insulation," Proc. CIGRE Session 1996, paper 15/33-06.

22. G.C. Stone, "Tutorial on Rotating Machine Off-line and On-line PD Testing," Coll. on Maintenance and Refurbishment of Utility Turbogenerators, Hydrogenerators, and Large Motors, Firenze, 1997.

23. G.C. Stone, H.G. Sedding, and M.J. Costello, "Application of PD Testing to Motor and Generator Stator Winding Maintenance," IEEE Trans. On Industry Applications, Vol. 32, No. 2, March/April 1996.

24. E. Gulski, H.P. Burger, A. Zielonka, and R. Brooks, "Classification of Defects in HV Components by Fractal Analysis of PD Measurements," CEIDP, San Francisco, USA, 1996.
25. F.H. Kreuger, "Detection and Location of Discharges in Particular in Plastic-Insulated High-Voltage Cables," thesis, Delft University, 1960, pp. 16-30.

26. E. Gulski, A.R. Samuel, L. Kehl, and H.T.F. Geene, "Digital Discharge Location in HV Cables with Traveling Wave System," 1996 IEEE International Symposium on EI, Montreal, Canada, 1996.

27. M. Mashikian, F. Palmieri, R. Bansal, R. Northrop, "Location of Partial Discharges in Shielded Cables in the Presence of High Noise," IEEE/DEIS Trans., February 1992.

28. R. Plath, "Oscillating Voltages als Prfspannung zur Vor-Ort-Prfung und TE-Messung kunstoffisolierter Kabel," Band 1, Verlag Dr. Koester, Berlin, 1994.

29. E. Lemke, P. Schmiegel, H. Elze, and D. Russwurm, "Procedure for Evaluation of Dielectric Properties Based on Complex Discharge Analyzing," IEEE International Symposium on EI, Montreal, Canada, 1996.

30. E. Pultrum, E. Hetzel, "VLF Discharge Detection as a Diagnostic Tool for MV Cables," IEEE PES 1997 Summer Meeting, Berlin, Germany, 1997.

31. J.T. Holboll and H. Edin, "PD Detection vs. Loss Measurement at HV with Variable Frequencies," 10th ISH, Montreal, Canada, 1997.

32. E. Gulski, J. J. Smit, P. N. Seitz, and J.C. Smit, "Partial Discharge Measurements On-site Using Oscillating Impulse Test System," IEEE International Symposium on EI, Washington, USA, 1998.

33. H.D. Schlemper, R. Kurrer, and K. Feser, "Sensitivity of On-Site PD Detection in GIS," 8th ISH, Yokohama, Japan, 1993

34. J.S. Pearson, O. Farish, B.F. Hampton, M.D. Judd, D. Tempelton, B.M. Pryor, and I.M. Welch, "PD Diagnostics for Gas Insulated Substations," IEEE Trans. On D and EI, Vol. 2, 1995, pp. 893-905.

35. S. Meijer, E. Gulski, J.J. Smit, and R. Brooks, "Comparison of Conventional and VHF/UHF Partial Discharge Detection Methods for $\mathrm{SF}_{6}$ Gas Insulated Systems," 10th ISH, Montreal, Canada, 1997.

36. S. Meijer, W.R. Rutgers, and J.J. Smit, "Acquisition of Partial Discharges in $\mathrm{SF}_{6}$ Insulation," CEIDP, San Francisco, USA, 1996.

37. E. Gulski, J.P. Zondervan, A. Zielonka, and R. Brooks, "PD Database for Stator Insulation of Turbogenerators," CEIDP, Minneapolis, USA, 1997.

38. E. Binder, H. Egger, A. Hummer, M. Muhr, and J. Schernthanner, "Predictive Maintenance of Generators," CIGRE Sess. 1992, pap. 11-305.

39. B. Fruth, G. Liptak, G T. Ulrich, and L. Niemeyer, "Ageing of Rotating Machines Insulation-Mechanisms, Measurement Techniques," Proc. $3 r d$ Conf. on Cond. and Breakd. in Solid Diel., 1989, Trondheim, July 3-6, pp. 597-601.

40. J. Fuhr, M Haessig, B. Fruth, and T. Kaiser, "PD-Fingerprints of Some HV Apparatus," Proc. of IEEE Int. Symp. on EI, Toronto, June 3-6, 1990, pp. 129-132.

41. J.P. Zondervan, E. Gulski, J.J. Smit, and R. Brooks, "PD Pattern Analysis of On-line Measurements on Rotating Machines," CEIDP, Minneapolis, USA, 1997.

42. V. Warren and G. Stone, "Recent Developments in Diagnostic Testing of Stator Windings," IEEE Electrical Insulation Magazine, September/ October 1998, Vol. 14, No 5. 